\title{
A sinalização das relações de coerência por conectores torna a identificação das relações mais fácil? Uma investigação do reconhecimento das relações pelos destinatários do discurso ${ }^{1}$
}

Signaling coherence relations by means of discourse markers makes identification of the relations easier? An investigation of the recognition of the relations by discourse addressees

Juliano Desiderato Antonio ${ }^{2}$

Universidade Estadual de Maringá (UEM), Maringá, Paraná, Brasil. jdantonio@uem.br

Resumo: Este trabalho tem como objetivo investigar se a falta de sinalização das relações de coerência por meio de conectores facilita ou dificulta a identificação dessas relações em aulas de curso superior. A investigação foi realizada com base na apresentação de dez excertos para professores. Inicialmente, os excertos foram apresentados aos informantes sem os conectores que ligam as porções textuais investigadas. $\mathrm{Na}$ sequência, os excertos foram apresentados com os conectores. Verificou-se que, na maioria das ocorrências, a identificação das relações pelos informantes foi possível mesmo sem o conector, corroborando o pressuposto da Teoria da Estrutura Retórica de que as relações de coerência podem ser estabelecidas e interpretadas independentemente de serem marcadas explicitamente por

${ }^{1}$ Este trabalho apresenta resultados de projeto de pesquisa financiado pela Fundação Araucária (Convênio 477/2014). Colaboraram com a pesquisa as acadêmicas Camila Cristiane Moreschi (PIC-UEM) e Virgínia Maria Nuss (PIBIC-UEM/CNPq).

${ }^{2}$ Universidade Estadual de Maringá. Programa de Pós-Graduação em Letras. Departamento de Teorias Linguísticas e Literárias. Av. Colombo, 5790 - Jd. Universitário. CEP 87020-900 - Maringá - PR. 
conectores. Apesar de conseguirem identificar as relações corretamente, os informantes consideraram que a sinalização das relações por meio de conectores facilita a identificação.

Palavras-chave: Funcionalismo; Teoria da Estrutura Retórica; relações de coerência.

Abstract: This paper aims to investigate if the lack of discourse markers to signal coherence relations makes the identification of the relations in undergraduate lectures more difficult or even impossible. The research was performed by presenting ten excerpts of undergraduate lectures for professors. Initially, the excerpts were presented to the informants without the connectors that combine the investigated text spans. Further, the excerpts were presented with the connectors. It was found that, in most instances, the identification of the relations by responders was possible even without the connector, supporting RST's assumption that coherence relations may be held and interpreted even without connectives. Although the informants were able to identify the relations correctly, they considered that signaling the relations by means of connectors facilitates identification.

Keywords: Functionalism; Rhetorical Structure Theory; coherence relations.

Recebido em: 14 de dezembro de 2014. Aprovado em: 15 de junho de 2015.

\section{Introdução}

A coerência textual pode ser avaliada, segundo Sanders, Spooren e Noordman (1992), levando-se em conta dois aspectos: o conteúdo das porções de texto ou as relações estabelecidas entre duas ou mais porções de texto. No primeiro caso, a coerência é obtida por meio da continuidade tópica ou referencial (GIVÓN, 1983; VAN DIJK; KINTSCH, 1983), por meio da congruência semântica entre as porções de texto (POLANYI, 1986) ou por meio da representação de padrões correspondentes a situações e eventos prototípicos no mundo representado no texto (SCHANK; ABELSON, 1977). No segundo caso, 
levam-se em conta as relações estabelecidas entre segmentos adjacentes na microestrutura textual (como orações, por exemplo, ou unidades de entonação, na língua falada, de acordo com CHAFE, 1985), ou entre segmentos de níveis mais altos (como porções de texto que atuam na macroestrutura ${ }^{3}$ textual, de acordo com VAN DIJK, 1992). Essas relações têm recebido várias denominações nos estudos linguísticos: predicados retóricos (GRIMES, 1975), proposições relacionais (MANN; THOMPSON, 1983), relações de coerência (HOBBS, 1985), relações retóricas (MANN; THOMPSON, 1988). ${ }^{4}$

O tratamento da coerência que interessa a esta pesquisa é o que diz respeito às relações entre duas ou mais porções de texto. Um tratamento adequado a essa questão das relações de coerência é oferecido pela RST (Rhetorical Structure Theory - Teoria da Estrutura Retórica), uma teoria descritiva que tem por objeto o estudo da organização dos textos, caracterizando as relações que se estabelecem entre as partes do texto (MANN; THOMPSON, 1988; MATTHIESSEN; THOMPSON, 1988; MANN, MATTHIESSEN; THOMPSON, 1992). A RST parte do princípio de que as relações retóricas que se estabelecem no nível discursivo organizam desde a coerência dos textos até a combinação entre orações (MATTHIESSEN; THOMPSON, 1988).

Ao tratar das relações retóricas tanto no nível discursivo quanto no nível gramatical (combinação entre orações), a RST demonstra sua filiação à Linguística Funcional, um grupo de teorias que consideram essencial para o estudo da língua a função dos elementos linguísticos na comunicação (BUTLER, 2003; NEVES, 1997a; NICHOLS, 1984). Podem ser observados na RST, de acordo com Antonio (2009a),

\footnotetext{
${ }^{3}$ Os conceitos de macroestrutura e superestrutura adotados neste trabalho tem base em Van Dijk e Kintsch (1983). Segundo esses autores, todo texto se organiza em dois planos textuais distintos. Um deles é de natureza semântica, chamado macroestrutura, e comporta as partes centrais de um texto; o outro é esquemático, chamado de superestrutura, e agrupa essas partes em uma ordem global. A macroestrutura tem relação com o sentido do texto, enquanto a superestrutura é um esquema textual abstrato, com formas relativamente fixas, composto por categorias vazias (preenchidas pela macroestrutura), que correspondem ao formato característico de um determinado tipo de texto.

${ }^{4}$ Neste trabalho, os termos relações retóricas e relações de coerência serão utilizados como equivalentes.
} 
pressupostos de outros modelos funcionalistas:

a) o modelo de análise top-down da Gramática SistêmicoFuncional de Halliday, partindo do texto para os níveis mais baixos da estrutura gramatical (VAN VALIN, 2002);

b) a motivação discursiva da gramática, observada nos trabalhos dos pesquisadores que compõem o grupo conhecido como Funcionalismo da Costa-Oeste dos EUA, entre os quais podem ser destacados alguns trabalhos, como Hopper e Thompson (1980), Givón (1983), Du Bois (1987), entre outros.

Uma lista de vinte e cinco relações foi estabelecida por Mann e Thompson (1988) após a análise de centenas de textos, por meio da RST. Essa lista não representa um rol fechado, mas um grupo de relações suficiente para descrever a maioria dos textos. ${ }^{5}$ tipos:

No que diz respeito à organização, as relações podem ser de dois

a) núcleo-satélite, nas quais uma porção do texto (satélite) é ancilar da outra (núcleo), como na Figura 1 a seguir, em que um arco vai da porção que serve de subsídio para a porção que funciona como núcleo.

b) multinucleares, nas quais uma porção do texto não é ancilar da outra, sendo cada porção um núcleo distinto, como na Figura 2 a seguir.

Figura 1 - Esquema de relação núcleo-satélite

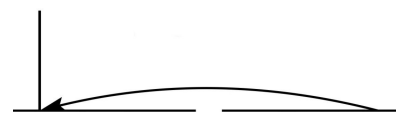

Fonte: MANN; THOMPSON, 1988.
Figura 2 - Esquema de relação multinuclear



${ }^{5}$ Uma lista com as relações e suas definições pode ser encontrada em: $<$ http://www.sfu.ca/rst/07portuguese/definitions.html $>$. 
As relações são definidas pela RST com base em quatro condições: a) restrições sobre o núcleo; b) restrições sobre o satélite; c) restrições sobre a combinação entre o núcleo e o satélite; d) efeito. Tome-se como exemplo a definição da relação elaboração apresentada no Quadro 1 a seguir.

Quadro 1 - Definição da relação de elaboração

\begin{tabular}{|c|c|c|c|}
\hline $\begin{array}{l}\text { Nome da } \\
\text { relação }\end{array}$ & $\begin{array}{l}\text { Restrições sobre } \\
\text { o núcleo ou } \\
\text { sobre o satélite } \\
\text { individualmente }\end{array}$ & $\begin{array}{l}\text { Restrições sobre } \\
\text { núcleo + satélite }\end{array}$ & $\begin{array}{l}\text { Intenção do } \\
\text { falante }\end{array}$ \\
\hline Elaboração & Nenhuma & $\begin{array}{l}\text { O satélite apresenta } \\
\text { detalhes adicionais } \\
\text { sobre a situação ou } \\
\text { sobre algum elemento } \\
\text { do assunto que é } \\
\text { apresentado no núcleo } \\
\text { ou é acessível } \\
\text { inferencialmente no } \\
\text { núcleo em uma ou mais } \\
\text { das maneiras listadas a } \\
\text { seguir. Na lista, se o } \\
\text { núcleo apresenta o } \\
\text { primeiro membro de } \\
\text { qualquer par, então o } \\
\text { satélite inclui o } \\
\text { segundo. } \\
\text { grupo :: membro } \\
\text { abstração :: instância } \\
\text { todo :: parte } \\
\text { processo :: passo } \\
\text { objeto :: atributo } \\
\text { generalização :: } \\
\text { específico. }\end{array}$ & $\begin{array}{l}\text { O destinatário } \\
\text { reconhece o satélite } \\
\text { como fornecendo } \\
\text { detalhes adicionais } \\
\text { para o núcleo. O } \\
\text { destinatário } \\
\text { identifica o } \\
\text { elemento do } \\
\text { assunto para o qual } \\
\text { o detalhe é } \\
\text { fornecido. }\end{array}$ \\
\hline
\end{tabular}

Fonte: MANN; TABOADA, 2010.

Como pode ser observado na definição, o uso da relação de elaboração tem por objetivo o acréscimo de informações, no satélite, a respeito do núcleo. Isso pode ser observado no diagrama arbóreo a seguir, que representa a análise da estrutura retórica de uma aula. As 
aulas que compõem o corpus do Grupo de Pesquisas Funcionalistas do Norte / Noroeste do Paraná (Funcpar) são constituídas por um tópico discursivo bastante amplo que representa o tema geral da aula. Esse supertópico é desenvolvido por meio de acréscimo de informações na forma de outros tópicos que o particularizam e que também são sucessivamente desenvolvidos por outros subtópicos.

A análise da estrutura retórica dessas aulas toma como base a ordenação tópica descrita acima. O supertópico é o núcleo que se encontra no nível mais alto na estrutura retórica de toda a aula. Os tópicos ${ }^{6}$ que o desenvolvem são satélites que acrescentam informações. $\mathrm{Na}$ camada seguinte da estrutura retórica, esses subtópicos, por sua vez, se tornam núcleos de outros subtópicos que os desenvolvem na forma de satélites. Essa organização pode ser observada no Diagrama 1 a seguir, que representa a macroestrutura de uma aula de físico-química do corpus.

\footnotetext{
${ }^{6}$ O conceito de tópico utilizado aqui baseia-se em Jubran et al. (1992, p. 361): “Tomado no sentido geral de 'acerca de' o tópico manifesta-se (...) mediante enunciados formulados pelos interlocutores a respeito de um conjunto de referentes explícitos ou inferíveis, concernentes entre si e em relevância num determinado ponto da mensagem".
} 
Diagrama 1 - Diagrama da estrutura retórica da macroestrutura de uma aula do corpus

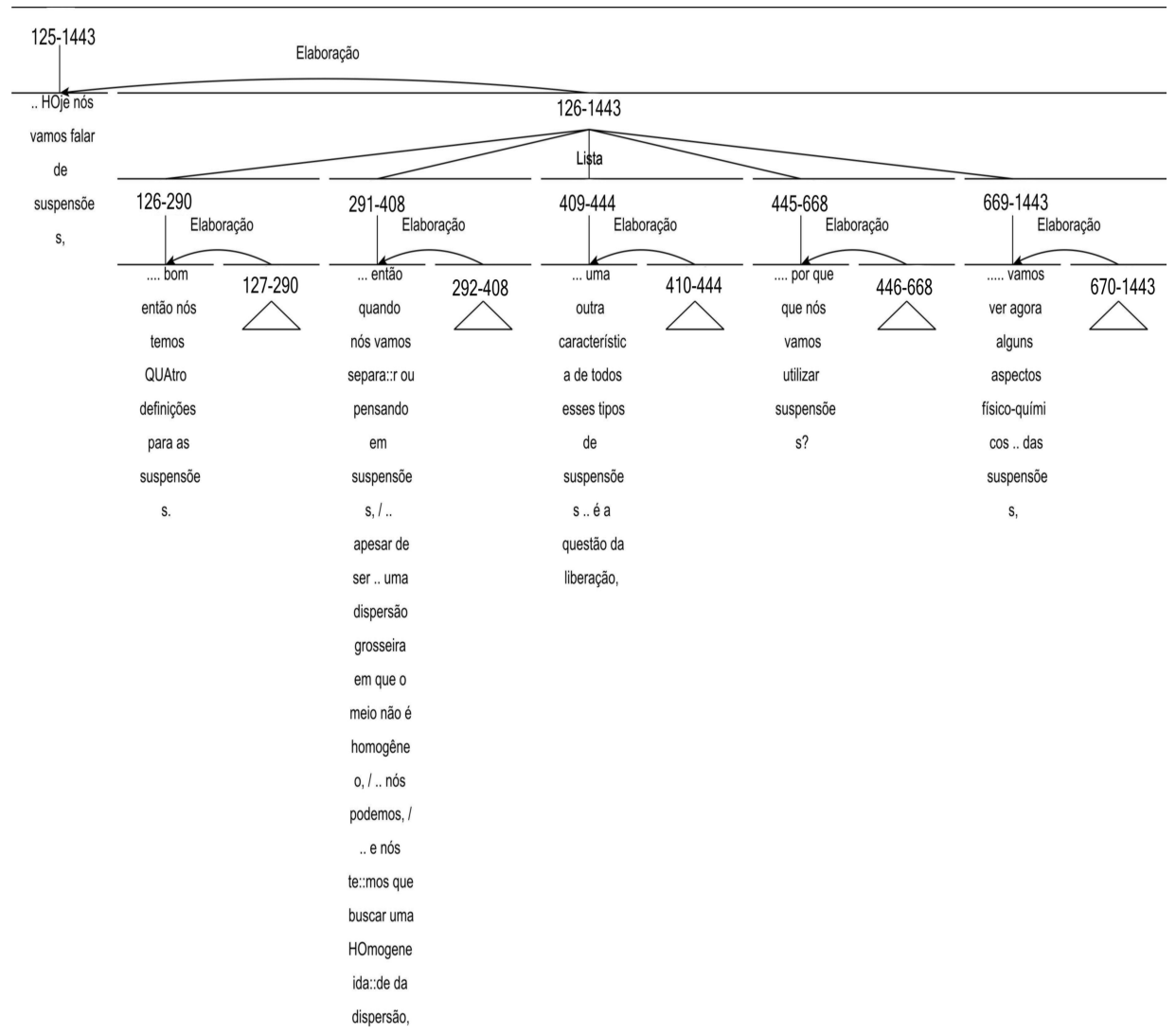

Fonte: ANTONIO; TAKAHASHI, 2010, p. 178.

Como pode ser observado no diagrama, o supertópico é anunciado pelo professor na unidade 125: "Hoje vamos falar de suspensões", ou seja, todos os conteúdos desenvolvidos durante a aula trarão informações sobre o tema "suspensões". Esses conteúdos são apresentados na forma de cinco satélites, que são os seguintes tópicos:

1) Definições das suspensões: unidades de 126 a 290;

2) Homogeneidade da suspensão: unidades de 291 a 408; 
3) Liberação: unidades de 409 a 444;

4) Por que utilizar suspensões: unidades de 446 a 668;

5) Aspectos físico-químicos das suspensões: unidades de 669 a 1443.

Cada um desses tópicos também é desenvolvido na camada seguinte da estrutura retórica. Por ser impossível transcrever neste espaço toda a aula, os satélites que desenvolvem cada um desses tópicos são representados por triângulos.

A análise da estrutura retórica da macroestrutura desses textos demonstra a importância do reconhecimento da proposição relacional de elaboração para o estabelecimento da coerência de texto. Caso o interlocutor do produtor do texto não perceba que as porções textuais que funcionam como satélite estão acrescentando informações a respeito do "assunto" em pauta, não conseguirá calcular a coerência do texto.

De acordo com a RST, as relações de coerência são implícitas e, portanto, são de sentido, e não de forma (MANN; THOMPSON, 1983), ou seja, as relações são estabelecidas e interpretadas independentemente de serem marcadas explicitamente por conectivos. Essas relações podem ser descritas com base na intenção comunicativa do enunciador e na avaliação que o enunciador faz do enunciatário, e refletem as escolhas do enunciador para organizar e apresentar os conceitos. A identificação dessas relações pelo analista, por sua vez, se baseia em julgamentos funcionais e semânticos, que buscam identificar a função de cada porção de texto, e verificar como o texto produz o efeito desejado em seu possível receptor.

Esses julgamentos são de plausibilidade, pois o analista tem acesso ao texto, tem conhecimento do contexto em que o texto foi produzido e das convenções culturais do produtor do texto e de seus possíveis receptores, mas não tem acesso direto ao produtor do texto ou aos seus possíveis receptores, de forma que não pode afirmar com certeza que esta ou aquela análise é a correta, mas pode sugerir uma análise plausível (MANN; THOMPSON, 1988).

Pesquisas realizadas no sentido de identificar os meios linguísticos utilizados pelos falantes para a sinalização das relações (GÓMEZ-GONZÁLEZ; TABOADA， 2005; TABOADA， 2006; 
TABOADA, 2009) têm demonstrado que alguns dos meios mais utilizados são os conectivos e os marcadores discursivos (MDs). Outros meios de sinalização sugeridos por essas autoras são marcas morfológicas, sintáticas, gráficas, de entonação (no caso da língua falada), de referência textual, do gênero textual etc. Em sua pesquisa a respeito da relação de contraste em diálogos, Ford (2000) observou que o significado das porções de texto também pode ser útil na identificação das relações.

Decat (2001), na primeira pesquisa utilizando a RST para a análise do português brasileiro $(\mathrm{PB})$, apresenta ocorrências nas quais a relação de condição emerge sem que se faça uso, por exemplo, do conectivo se ou equivalente. Trata-se de construções como "Leite com manga, morre", "Bateu, levou". No corpus do Funcpar, também há ocorrências da relação de condição sem a utilização de conectivo, como no Diagrama 2, que apresenta uma ocorrência encontrada em uma aula de Geografia. Nessa ocorrência, a repetição é expressa por meio de paralelismo sintático. O professor fala sobre migrações no Brasil motivadas por desenvolvimento econômico. Ele afirma que se a economia estava se desenvolvendo no Nordeste, as pessoas iriam para aquela região. E a mesma estrutura pergunta-resposta é repetida para as demais regiões: Norte, Centro, Sul, Sudeste. Pode-se observar que a relação de condição não é marcada por conectivo. 
Diagrama 2 - Relação de condição não sinalizada por conectivo

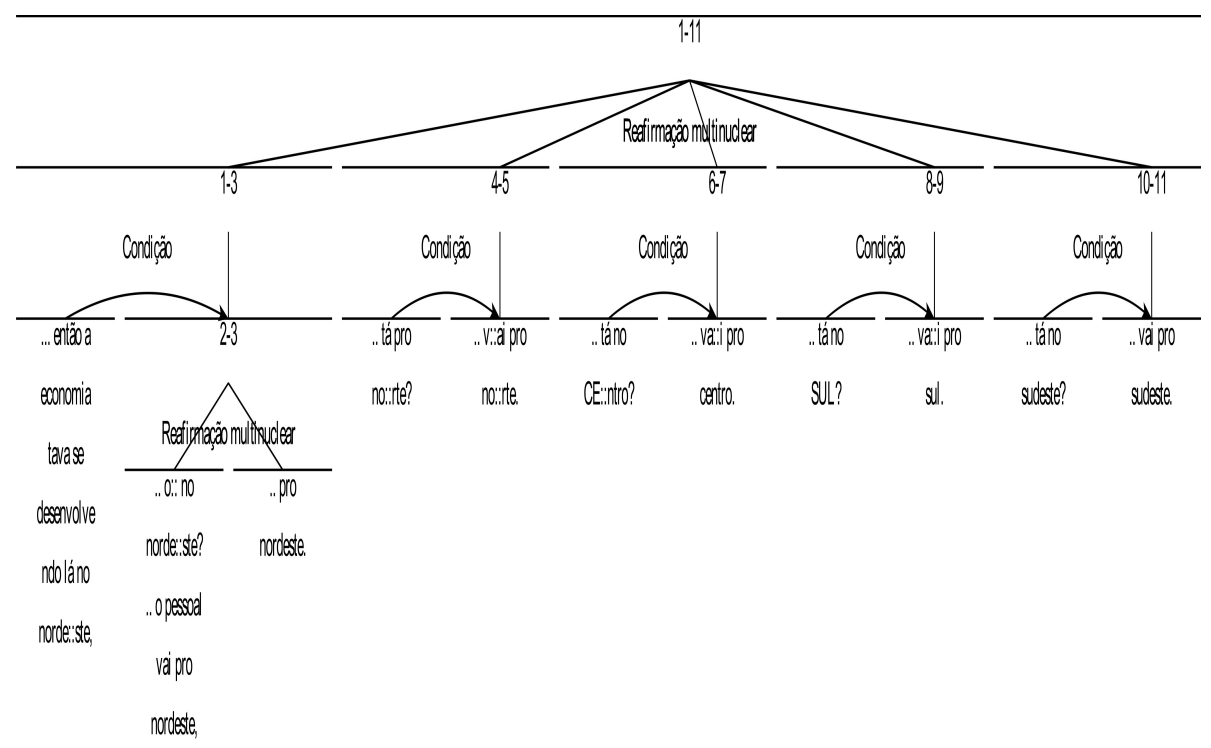

Fonte: ANTONIO; CASSIM, 2012, p. 87.

Por outro lado, no Diagrama 3, que apresenta uma ocorrência encontrada em uma aula de Biologia, a relação de condição é sinalizada pela conjunção $s e$.

Diagrama 3 - Relação de condição sinalizada pela conjunção se

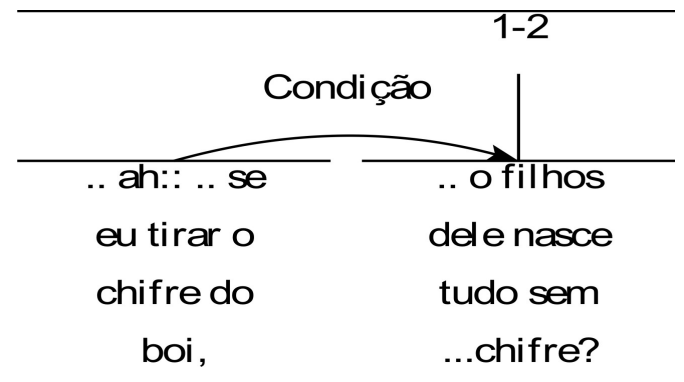

Fonte: ANTONIO, 2012a, p. 135. 
Um outro exemplo pode ser observado no Diagrama 4, em que a relação de condição é sinalizada por meio da conjunção quando, considerada um conectivo temporal. A identificação da relação de condição é possível não pelo emprego da conjunção quando, mas pelo fato de a construção apresentar os traços não factual e não pressuposta. ${ }^{7}$ Dessa forma, essa ocorrência corresponde aos casos de orações temporais com leitura condicional a que se referem Neves (2000) e Hirata-Vale (2008). Quando o evento codificado na oração temporal ocorre, preenche a condição para que o evento na oração nuclear ocorra também.

Diagrama 4 - Relação de condição sinalizada pela conjunção quando

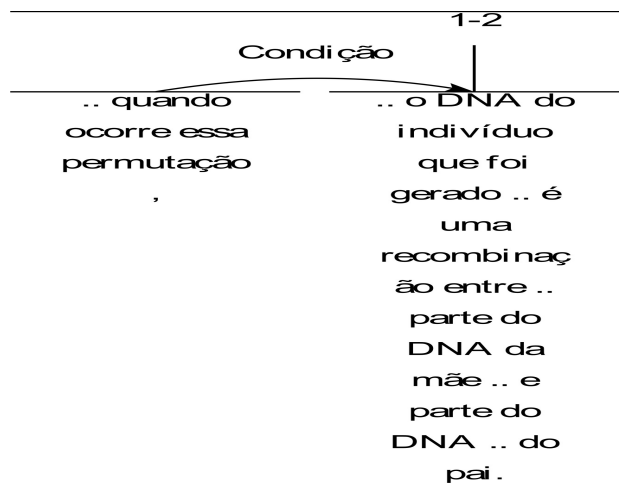

Fonte: ANTONIO, 2012a, p. 137.

É com base nessas observações que se propõe a pergunta que justificou a realização desta pesquisa: a falta de sinalização das relações por meio de conectivos e de MDs dificulta ou impossibilita a identificação dessas relações em aulas de curso superior?

${ }^{7}$ Pérez Quintero (2002) considera como factuais: (a) estados-de-coisas descritos como reais, (b) conteúdos proposicionais descritos como verdadeiros, (c) atos discursivos descritos como assertivos. No que diz respeito à pressuposição, Hengeveld (1998, p. 353) afirma que, "no domínio não-factual, a pressuposição leva à contrafactividade, isto é, à pressuposição de que um evento é irreal ou de que o contéudo proposicional é falso". 


\section{Metodologia}

A investigação foi realizada com a apresentação de dez excertos para professores de curso superior. Para cada excerto apresentado, os informantes responderam algumas perguntas para que se pudesse verificar se a relação foi reconhecida.

Os excertos foram retirados do corpus de pesquisa do Grupo de Pesquisas Funcionalistas do Norte / Noroeste do Paraná (Funcpar), constituído por elocuções formais (aulas) e entrevistas.

Por se tratar de um corpus de língua falada, as porções de texto apresentadas para os informantes da pesquisa foram retextualizadas, ou seja, retiraram-se as marcas do processo de produção oral (MARCUSCHI, 2001), como pode ser observado no exemplo a seguir.

.. LER é uma coisa prazero:.sa ... tal,

.. estudar é uma coisa prazerosa.

.. agora ESCREVER já:: ... faço por obrigação e pressionado.

Essa porção, depois de ser retextualizada, foi apresentada aos informantes da seguinte maneira:

Ler é uma coisa prazerosa, estudar é uma coisa prazerosa. Agora, escrever já faço por obrigação e pressionado.

A escolha de professores de curso superior como informantes se justifica pelo fato de as elocuções formais do corpus terem esse público como produtor. Tentou-se, dessa forma, evitar que a falta de informação pragmática fosse um fator que atrapalhasse a compreensão das porções de texto apresentadas aos informantes.

Inicialmente, os excertos foram apresentados aos informantes sem os conectores que ligam as porções textuais investigadas. $\mathrm{Na}$ sequência, os excertos foram apresentados com os conectores. Deve-se observar que os excertos foram produzidos originalmente com os conectores, que foram retirados para os propósitos da pesquisa quando da apresentação inicial aos informantes. 
A pergunta feita aos informantes foi: "Que relação de sentido há entre os enunciados 'Ler é uma coisa prazerosa, estudar é uma coisa prazerosa' e 'escrever já faço por obrigação e pressionado'?". Na sequência, apresentou-se o mesmo excerto com o MD agora e perguntou-se aos informantes se a utilização do MD tornava a compreensão do excerto e a identificação da relação mais fácil.

\section{Resultados e Discussão}

Excerto 1

(1) Ler é uma coisa prazerosa, estudar é uma coisa prazerosa.

(2) Escrever já faço por obrigação e pressionado.

No primeiro excerto apresentado aos informantes da pesquisa, a relação que emerge entre as porções textuais é de contraste, conforme análise de Antonio (2009b, p. 211).

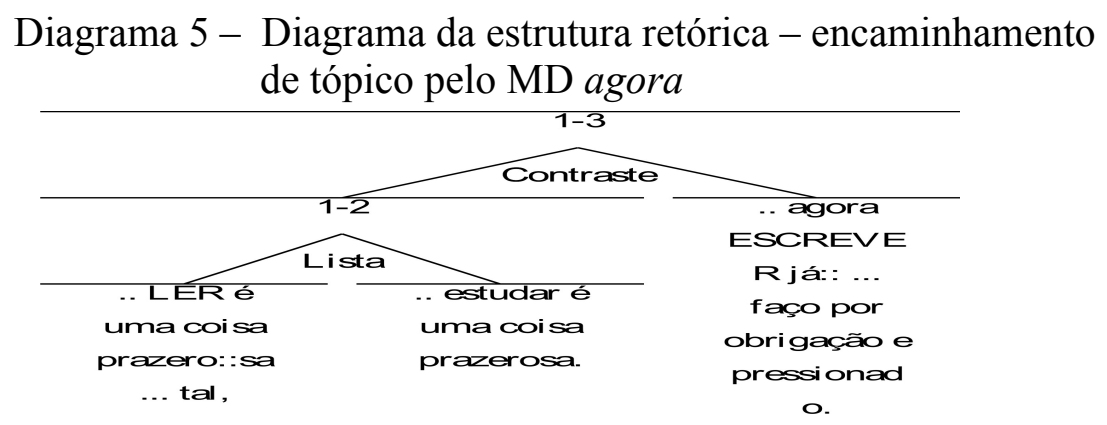

Fonte: ANTONIO, 2009b, p. 211.

No exemplo, o falante trata de suas atividades como docente. Menciona seu apreço pela leitura e pelo estudo por meio de cláusulas que apresentam essas duas atividades como tendo um mesmo estatuto (unidades 1 e 2). Em seguida, contrasta o prazer de ler e de estudar com a obrigação profissional de escrever (unidade 3). O contraste é marcado pelo MD agora iniciando a unidade 3. 
Analisando-se as funções do MD agora à luz da RST, verificouse que, ao atuar no encaminhamento de tópico (mudança de orientação no interior do tópico discursivo), o agora estabelece relação de contraste entre porções de texto multinucleares. A definição da relação de contraste pode ser observada no Quadro 2.

Quadro 2 - Definição da relação de contraste

\begin{tabular}{|c|c|c|}
\hline $\begin{array}{l}\text { Nome da } \\
\text { relação }\end{array}$ & Restrições sobre cada par de núcleos & Intenção do falante \\
\hline Contraste & $\begin{array}{l}\text { Não mais do que dois núcleos; as situações } \\
\text { nesses núcleos são (a) compreendidas como } \\
\text { semelhantes em vários aspectos; (b) } \\
\text { compreendidas como diferindo em alguns } \\
\text { aspectos; e (c) comparado com respeito a } \\
\text { uma ou mais dessas diferenças. }\end{array}$ & $\begin{array}{l}\text { O destinatário } \\
\text { reconhece a } \\
\text { comparabilidade e as } \\
\text { diferenças levantadas } \\
\text { pela comparação } \\
\text { sendo feita. }\end{array}$ \\
\hline
\end{tabular}

Fonte: MANN: TABOADA, 2010.

Oito dos dez informantes identificaram a relação de contraste, utilizando termos como contraste, contradição, oposição, ideias contrárias. Ao ser apresentado o excerto com o MD agora, os dois informantes que não haviam identificado a relação como sendo de contraste passaram a identificá-la corretamente. Entre os informantes que identificaram a relação corretamente antes da apresentação do excerto com o MD agora, três afirmaram que a utilização desse MD não faria diferença para a compreensão da relação, quatro consideraram que o MD facilita, esclarece ou explicita a relação. Por fim, um informante com uma postura mais conservadora em relação ao uso dos elementos linguísticos, afirmou que o falante não deveria utilizar o vocábulo agora se não fosse para expressar a noção de tempo.

\section{Excerto 2}

(1) No canto inferior da página, vocês vão colocar "Psicologia Experimental e Análise do Comportamento",

(2) é o nome da disciplina.

No segundo excerto apresentado aos informantes, a relação que emerge da combinação das porções de texto é a de elaboração (cf. 
definição no QUADRO 1 deste trabalho), na microestrutura, mais especificamente na gramática da combinação de orações, conforme análise apresentada por Antonio e Takahashi (2010, p. 179).

Diagrama 6 - Relação de elaboração estabelecida entre oração adjetiva explicativa e oração nuclear

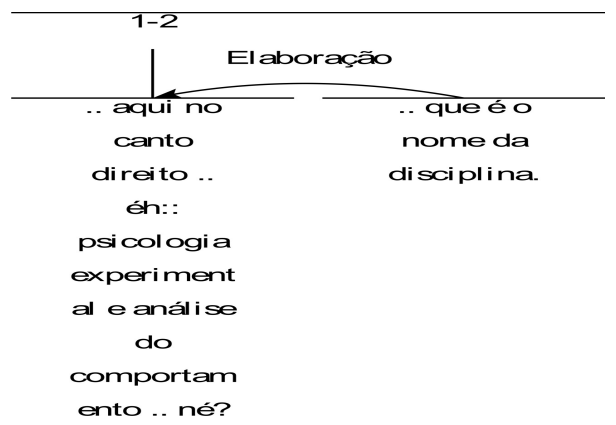

Fonte: ANTONIO; TAKAHASHI, 2010, p. 179.

A relação se estabelece entre uma oração explicativa e uma oração nuclear: nesse caso, a oração adjetiva funciona como satélite que acrescenta informações ao núcleo. Essa análise é corroborada por Neves (2000, p. 375), que afirma que uma oração adjetiva explicativa "introduz uma informação adicional". Observe-se que, nesse exemplo, a oração que funciona como satélite acrescenta uma informação sobre o referente "psicologia experimental e análise do comportamento", mencionado na oração nuclear.

Todos os informantes identificaram corretamente a relação de elaboração, afirmando que a porção 2 acrescentava informações à porção 1 , explicava a porção 1 ou identificava um termo da porção 1 . Ao se apresentar o excerto com o conectivo que, nove dos dez informantes afirmaram que o uso do conectivo esclarece, facilita a compreensão da relação, tornando a compreensão mais objetiva, mais clara.

Excerto 3

Antigamente no Brasil era assim: você chegava e pegava a terra, não tinha lei.

(1) Você vencia os índios, 
(2) ficava com a terra pra você.

Ao serem indagados a respeito do excerto 3 (DIAGRAMA 7, caso de parataxe condicional), cinco informantes identificaram a relação de condição (cf. definição no QUADRO 3), quatro informantes identificaram a relação de causa-consequência, e um informante apenas parafraseou o excerto sem identificar qualquer relação. As respostas dos informantes corroboram a afirmação de Neves (2000) de que as construções concessivas, as construções causais e as construções condicionais situam-se em um mesmo contínuo semântico. De acordo com a autora, há um extremo em que a relação de causa é afirmada (construções causais), um extremo em que o vínculo causal entre as orações é negado (construções concessivas) e um espaço intermediário em que a relação de causa entre as orações é hipotetizada (condicionais).

Diagrama 7 - Relação de condição estabelecida em uma construção paratática condicional

\section{$1-2$}

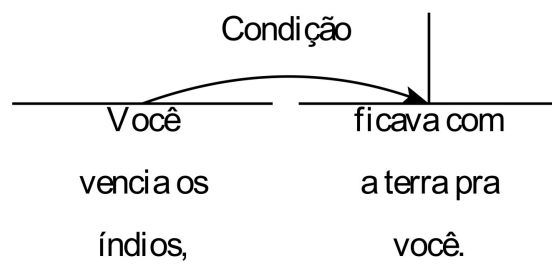

Fonte: o autor.

Quadro 3 - Definição da relação de condição

\begin{tabular}{l|l|l|l}
\hline $\begin{array}{l}\text { Nome da } \\
\text { relação }\end{array}$ & $\begin{array}{l}\text { Restrições sobre o núcleo ou } \\
\text { sobre o satélite } \\
\text { individualmente }\end{array}$ & $\begin{array}{l}\text { Restrições } \\
\text { sobre núcleo } \\
\text { satélite }\end{array}$ & $\begin{array}{l}\text { Intenção do } \\
\text { falante }\end{array}$ \\
\hline Condição & $\begin{array}{l}\text { Sobre S: S apresenta uma } \\
\text { situação realização de } \\
\text { hipotética, futura (relativa ao } \\
\\
\text { contexto situacional de S). }\end{array}$ & $\begin{array}{l}\text { destinatário } \\
\text { realização de S. }\end{array}$ & $\begin{array}{l}\text { realização de N } \\
\text { depende de da } \\
\text { realização de S. }\end{array}$ \\
\hline
\end{tabular}

Fonte: MANN; TABOADA, 2010. 
Ao se apresentar a versão com o conectivo se, prefaceando a primeira oração da construção (se você vencia os índios), os quatro informantes que haviam dito que a relação era de causa-consequência alteraram a leitura para condição. Questionados a respeito da mudança, afirmaram reconhecer uma proximidade semântica entre as relações. Entre os cinco informantes que identificaram a relação como de condição, apenas um disse que o conectivo se era desnecessário, os demais afirmaram que o conectivo tornava a identificação mais clara, mais direta.

\section{Excerto 4}

Há alguns anos, fizeram uma pesquisa sobre soja transgênica com dois grupos de homens: dez homens se alimentaram com soja transgênica e outros dez homens com soja convencional.

(1) Acabou o período de teste,

(2) foram fazer o diagnóstico daquelas pessoas.

No caso do excerto 4, a relação de circunstância emerge da combinação entre as orações (DIAGRAMA 8). Como pode ser observado na definição da relação de circunstância no Quadro 4, o satélite cria uma moldura em que será interpretado o evento do núcleo.

Diagrama 8 - Relação de circunstância.

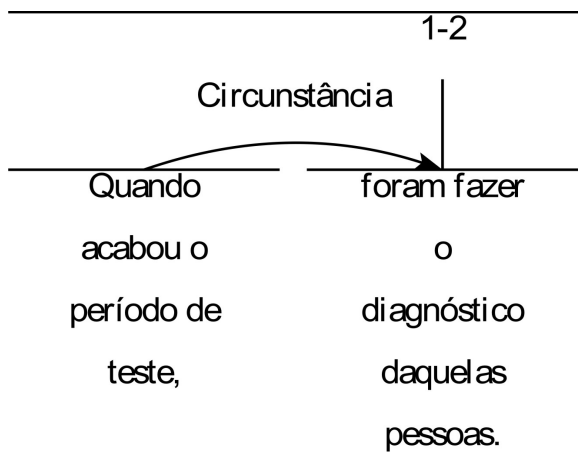

Fonte: o autor. 
Quadro 4 - Definição da relação de circunstância

\begin{tabular}{l|l|l|l}
\hline $\begin{array}{l}\text { Nome da } \\
\text { relação }\end{array}$ & $\begin{array}{l}\text { Restrições sobre o } \\
\text { núcleo ou sobre o } \\
\text { satélite } \\
\text { individualmente }\end{array}$ & $\begin{array}{l}\text { Restrições sobre } \\
\text { núcleo + satélite }\end{array}$ & $\begin{array}{l}\text { Intenção do } \\
\text { falante }\end{array}$ \\
\hline Circunstância & $\begin{array}{l}\text { Sobre S: S não é não } \\
\text { realizado. }\end{array}$ & $\begin{array}{l}\text { S determina uma } \\
\text { moldura para } \\
\text { assunto em que o } \\
\text { destinatário pretende } \\
\text { interpretar N. }\end{array}$ & $\begin{array}{l}\text { O destinatário } \\
\text { reconhece que S } \\
\text { fornece uma } \\
\text { moldura para a } \\
\text { interpretação de N. }\end{array}$ \\
\hline
\end{tabular}

Fonte: MANN; TABOADA, 2010.

Oito dos dez informantes da pesquisa identificaram relação temporal entre as orações. Ao se apresentar o excerto com o conectivo quando, os dois informantes que não haviam identificado a relação corretamente alteraram a reposta para relação temporal. E todos os informantes que haviam identificado a relação corretamente afirmaram que o conectivo quando facilita o reconhecimento da relação.

\section{Excerto 5}

O que são as suspensões secas extemporâneas?

(1) A geração de vocês é geração amoxil. O amoxil já vem líquido prontinho? Colocava água filtrada e agitava, não era? Aquilo é uma suspensão: ficava grosso, vocês sentiam os cristais, a amoxicilina vai estar dispersa na água, não dissolve. Essa suspensão aquosa não é muito estável, então o fabricante retirou a água. Assim, o tempo durante o qual ela fica armazenada na fábrica, no depósito, na distribuidora, na farmácia, até você comprar ela se torna estável.

Ao colocar a água, você refaz a suspensão, só que ela é uma suspensão extemporânea: temporâneo de tempo, ou seja, prazo curto de validade. Um antibiótico, por exemplo amoxicilina, depois de refeito, tem quinze dias de validade, que é o tempo que você vai utilizar o medicamento. Depois pode descartar.

(2) Formulações extemporâneas, prazo de validade curto.

No excerto 5, retirado de uma aula do curso de Farmácia, a relação que emerge entre as porções textuais 1 e 2 (cf. DIAGRAMA 9) é de resumo (cf. definição no QUADRO 5). O professor resume, na 
unidade 2, o que foi explicado na unidade 1, ou seja, que formulações extemporâneas têm prazo de validade curto (ANTONIO; ALVES, 2013, p. 192).

Diagrama 9 - Relação de resumo

Fonte: ANTONIO; ALVES, 2013, p. 192

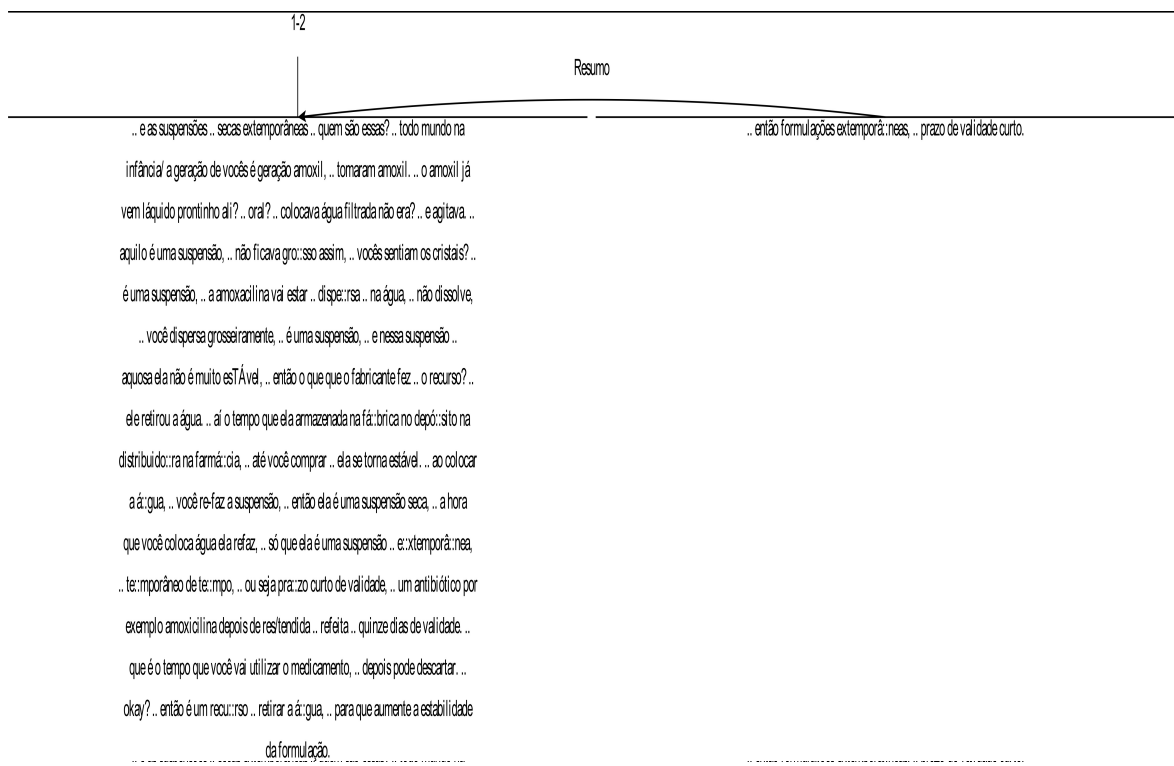

Quadro 5 - Definição da relação de resumo

\begin{tabular}{l|l|l|l}
\hline $\begin{array}{l}\text { Nome } \\
\text { da } \\
\text { relação }\end{array}$ & $\begin{array}{l}\text { Restrições sobre o } \\
\text { núcleo ou sobre o } \\
\text { Satélite } \\
\text { individualmente }\end{array}$ & $\begin{array}{l}\text { Restrições sobre } \\
\text { núcleo + satélite }\end{array}$ & $\begin{array}{l}\text { Intenção do } \\
\text { falante }\end{array}$ \\
\hline Resumo & $\begin{array}{l}\text { Sobre N: N deve ser } \\
\text { mais do que uma }\end{array}$ & $\begin{array}{l}\text { S apresenta uma } \\
\text { reformulação do } \\
\text { conteúdo de N, com } \\
\text { unidade }\end{array}$ & $\begin{array}{l}\text { O destinatário } \\
\text { reconhece S } \\
\text { como uma } \\
\text { reformulação } \\
\text { mais abreviada } \\
\text { de N }\end{array}$ \\
\hline
\end{tabular}

Fonte: MANN; TABOADA, 2010. 
Seis dos dez informantes identificaram a relação como sendo de resumo, dois definiram a relação como sendo de conclusão, e dois informantes afirmaram que a unidade dois era uma explicação da unidade 1 . Ao se apresentar aos informantes o excerto com a unidade 2 iniciada pelo MD então, um dos informantes que haviam afirmado que a relação era de explicação alterou sua resposta para conclusão. Os demais informantes foram unânimes em afirmar que o MD então facilita a compreensão da relação de resumo.

Se se considerar que as relações de resumo e de conclusão estão de alguma forma associadas, após a apresentação do excerto com o MD então, pode-se observar que nove dos dez informantes reconheceram a função da porção que funciona como satélite. A relação de conclusão não faz parte do rol de relações proposto inicialmente pelos autores da RST (MANN; THOMPSON, 1988), mas foi definida posteriormente por Pardo (2005). Pode-se hipotetizar que, antes da definição dessa relação, muitas das ocorrências de conclusão eram anotadas como sendo de resumo. Partindo da perspectiva de outra teoria funcionalista, a Gramática Discursivo-Funcional - GDF (HENGEVELD; MACKENZIE, 2008), Novaes-Marques (2014) também propõe que resumo e conclusão estão relacionadas, e que o resumo é uma função sob o escopo da relação de conclusão.

\section{Excerto 6}

Como você explicaria ou que nome você daria à relação de sentido que se estabelece entre os trechos (1) e (2) a seguir? O que ajudou você a reconhecer essa relação?

(1) Os frangos estão sendo abatidos muito cedo.

(2) O negócio é exportar.

No excerto 6, a relação estabelecida entre as porções é de causa não volitiva (cf. DIAGRAMA 10). Na análise apresentada por Antonio (2012b, p. 262), a relação causal é estabelecida entre dois eventos no mundo (estados de coisas), a saber, o abate precoce de frangos é causado pelo aumento na exportação, mas o sujeito da oração principal não age voluntariamente (cf. definição da relação no QUADRO 6). 
Diagrama 10 - Relação de causa não volitiva.

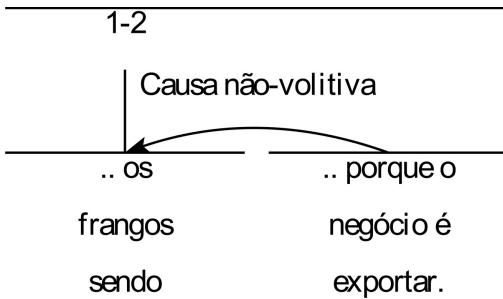

abatidos

muito cedo,

Fonte: ANTONIO, 2012b, p. 262.

Quadro 6 - Definição da relação de causa não volitiva.

\begin{tabular}{l|l|l|l}
\hline $\begin{array}{l}\text { Nome da } \\
\text { relação }\end{array}$ & $\begin{array}{l}\text { Restrições sobre } \\
\text { N ou sobre S } \\
\text { individualmente }\end{array}$ & Restrições sobre N + S & $\begin{array}{l}\text { Intenção do } \\
\text { falante / escritor }\end{array}$ \\
\hline $\begin{array}{l}\text { Causa } \\
\text { não }\end{array}$ & $\begin{array}{l}\text { Sobre N: N é uma } \\
\text { ação não volitiva. }\end{array}$ & $\begin{array}{l}\text { S, por outros meios que não } \\
\text { motivar uma ação volitiva, } \\
\text { volitiva }\end{array}$ & $\begin{array}{l}\text { O destinatário } \\
\text { reconhece S como a } \\
\text { de S, o destinatário poderia } \\
\text { não reconhecer a causa } \\
\text { particular de uma situação; a } \\
\text { apresentação de N é mais } \\
\text { central para os propósitos do } \\
\text { falante do que apresentar a } \\
\text { combinação N-S. }\end{array}$ \\
\hline
\end{tabular}

Fonte: MANN; TABOADA, 2010.

Sem o conectivo porque e sem mais informações que pudessem subsidiar sua interpretação, esse excerto foi um dos mais desafiadores para os informantes da pesquisa. Quatro informantes identificaram a relação de causa ou de justificativa, dois interpretaram que havia um problema (frangos sendo abatidos muito cedo) e uma solução (exportar), um identificou a relação de propósito (abater cedo para exportar). Sem o conectivo, as leituras de problema-solução e propósito são plausíveis. Dois informantes apontaram a relação de explicação, e um apontou a relação de conclusão. Após a apresentação do excerto com o conectivo porque iniciando a unidade 2 , sete informantes alteraram a resposta para 
justificativa ou causa, e todos os informantes reconheceram a importância do conectivo nesse excerto.

\section{Excerto 7}

(1) Tudo chega no meio científico, e o resultado ainda não chegou na população, mas que a população tem acesso há pouquíssimo tempo, isso tem, e desconhece até hoje.

(2) Esses dias eu estava em um congresso, na amostra tecnológica que teve aqui na universidade, e uma senhora chegou para mim e falou assim "a gordura trans é uma gordura TRANSFORMADA, não é?"

No excerto 7, a relação estabelecida pela porção textual 2 em relação à porção textual 1 é de evidência, de acordo com análise apresentada por Antonio (2012b, p. 265) (DIAGRAMA 11). De acordo com a definição da relação (QUADRO 7), a intenção do falante ao utilizar essa relação é aumentar a confiança do destinatário no conteúdo do núcleo. Dessa forma, para que o destinatário acredite no conteúdo do núcleo, um exemplo do que foi afirmado no núcleo é apresentado no satélite.

Diagrama 11 - Relação de evidência.

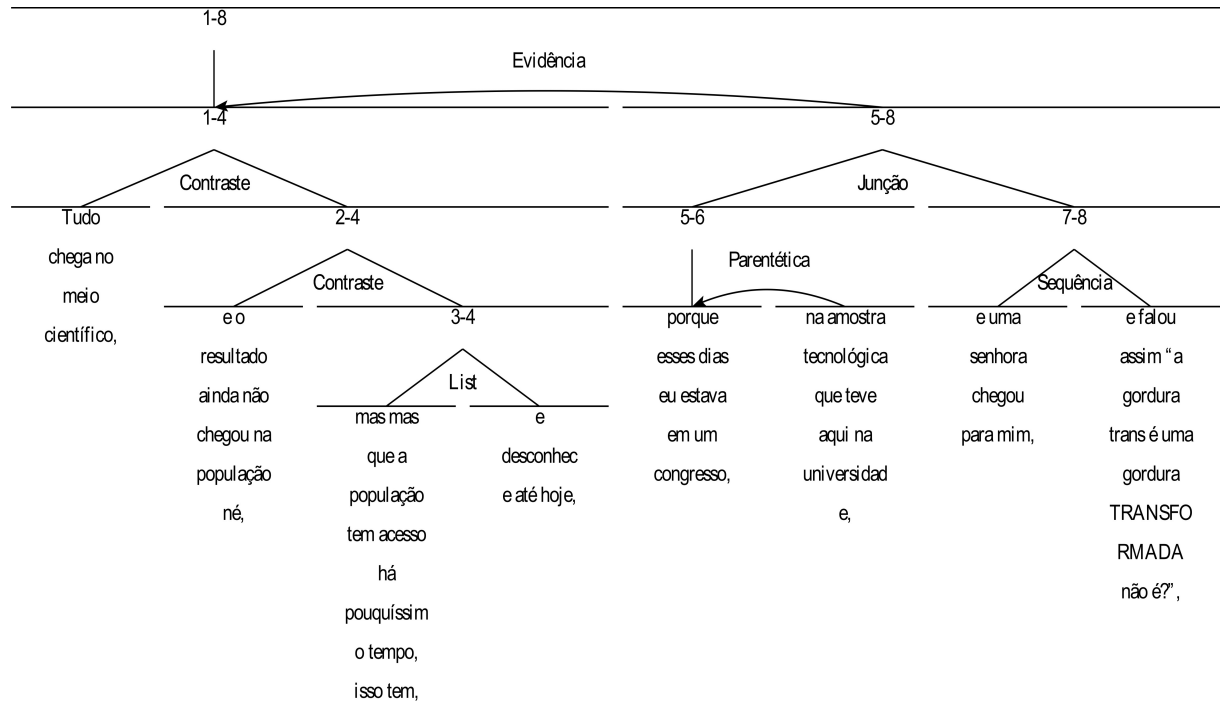

Fonte: o autor. 
Quadro 7 - Definição da relação de evidência

\begin{tabular}{l|l|l|l}
\hline $\begin{array}{l}\text { Nome da } \\
\text { relação }\end{array}$ & $\begin{array}{l}\text { Restrições sobre N ou } \\
\text { sobre S individualmente }\end{array}$ & $\begin{array}{l}\text { Restrições sobre } \\
\mathbf{N}+\mathbf{S}\end{array}$ & $\begin{array}{l}\text { Intenção do } \\
\text { falante/escritor }\end{array}$ \\
\hline Evidência & Sobre N: o destinatário & Compreendendo & A confiança do \\
& poderia não acreditar em N a & S, aumenta a & destinatário em N \\
& um grau satisfatório para o & confiança do & aumenta. \\
& falante. & destinatário em & \\
& Sobre S: o destinatário & N. & \\
& acredita em S. & & \\
\hline
\end{tabular}

Fonte: MANN; TABOADA, 2010.

Todos os informantes identificaram a relação estabelecida pelo satélite no excerto, afirmando que a porção 2 exemplificava o conteúdo da porção 1. Ao se apresentar o excerto com o porque prefaceando o satélite, três informantes afirmaram que não haveria necessidade de conectivo no excerto, pois perceberam que o item porque, nesse excerto, não é uma conjunção causal ou explicativa, mas um MD. Tal observação teve como base uma postura mais conservadora em relação ao uso dos elementos linguísticos, segundo a qual um item como porque não deveria introduzir exemplos, mas orações causais ou explicativas. Os demais informantes consideraram que o conectivo torna a compreensão da relação mais clara ou prepara melhor o destinatário para a porção que vem na sequência.

\section{Excerto 8}

(1) Eu fervi o caldo, deixei o caldo bem gostosinho pras bactérias,

(2) não apareceu nenhuma bactéria.

No excerto 8 , a relação que emerge da combinação entre as porções de texto é a relação de contraste (cf. QUADRO 2). O estado de coisas da unidade 1 cria a expectativa de que um ambiente propício para as bactérias favorecerá o aparecimento desse microorganismo, mas essa expectativa é frustrada pelo estado de coisas da unidade 2, como pode ser observado no diagrama 12. 
Diagrama 12 - Relação de contraste.



Fonte: o autor.

Seis informantes identificaram o contraste ou a quebra de expectativa, outros informantes mencionaram relações não plausíveis como causa e consequência, explicação, conclusão e esclarecimento. Ao se depararem com a unidade 2 iniciada por $e$, três informantes alteraram a leitura que haviam feito inicialmente, mas apenas um indicou corretamente a relação de contraste. E dos seis informantes que haviam identificado a relação corretamente, apenas um afirmou que a inclusão do $e$ facilitava a compreensão. É provável que os informantes não tenham achado necessária a inclusão do $e$, porque esse conectivo é prototípico da coordenação aditiva. Como, nesse caso, o $e$ foi utilizado pelo falante para sinalizar a relação de contraste, alguns informantes disseram ter estranhado esse uso do $e$. No entanto, há registros de outros valores semânticos associados ao conectivo $e$, além do aditivo, como o adversativo e o conclusivo, de acordo com Schiffrin (1986), em pesquisa a respeito do and no inglês.

\section{Excerto 9}

Todo sal que a humanidade ingeria era proveniente dos alimentos, dos vegetais, da própria carne. Com o passar do tempo, o que o homem fez? 
(1) Foi lá no mar, concentrou sal

(2) jogou no alimento.

No excerto 9, a relação de sequência emerge da combinação entre as porções textuais (DIAGRAMA 13). Como pode ser observado na definição da relação (QUADRO 8), há sucessão temporal entre os eventos dos núcleos.

Diagrama 13 - Relação de sequência

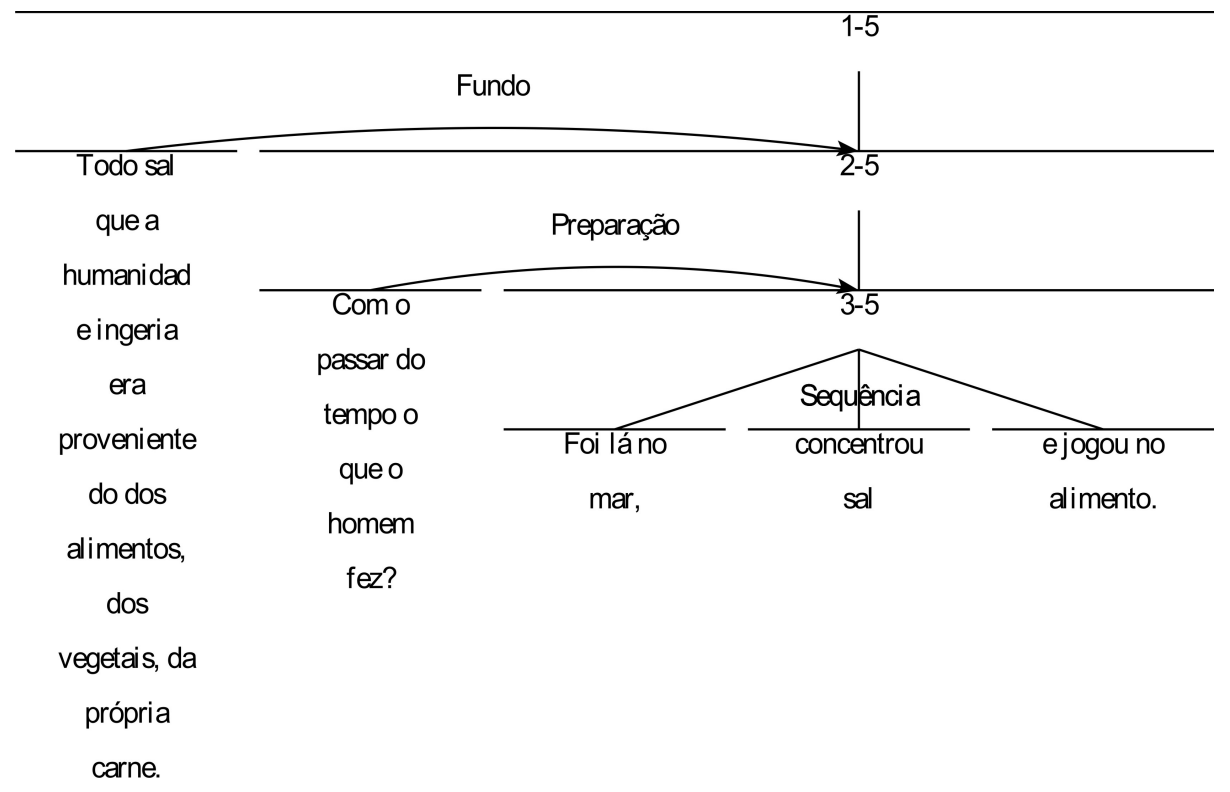

Fonte: o autor.

Quadro 8 - Definição da relação de sequência

\begin{tabular}{l|l|l}
\hline $\begin{array}{l}\text { Nome da } \\
\text { relação }\end{array}$ & Condições em cada par de N & Intenção do falante \\
\hline Sequência & $\begin{array}{l}\text { Existe uma relação de sucessão entre } \\
\text { as situações apresentadas nos } \\
\text { núcleos }\end{array}$ & $\begin{array}{l}\text { O destinatário reconhece as } \\
\text { relações de sucessão entre os } \\
\text { núcleos. }\end{array}$ \\
\hline
\end{tabular}

Fonte: MANN; TABOADA, 2010. 
Sete informantes identificaram corretamente a relação de sucessão temporal entre os núcleos, um informante não respondeu, e dois informantes identificaram relações não plausíveis para o excerto (solução e explicação). Após a apresentação do excerto com o conectivo $e$ introduzindo a unidade 2 , nenhum informante alterou a leitura que havia feito, e três dos informantes que haviam identificado corretamente a relação afirmaram que o conectivo não era importante para a compreensão. Pode-se postular a hipótese de que a multiplicidade de valores semânticos assumidos pelo $e$, conforme mencionado anteriormente, leve os falantes a considerar que o $e$, por não proporcionar uma identificação biunívoca das relações, não seja tão determinante para a compreensão.

\section{Excerto 10}

(1)Uma outra discussão começa a se levantar: esses primeiros seres eram autotróficos ou heterotróficos?

(2) Vamos lembrar dos termos?

Organismo autotrófico é aquele que produz o seu próprio alimento, e o organismo heterotrófico não produz seu próprio alimento, tem que obter esse alimento do meio.

No excerto 10, o professor trata dos primeiros organismos na Terra. Ele pergunta aos alunos se esses organismos eram autotróficos ou heterotróficos (unidades 1 e 2). Como o professor não sabia se os alunos conheciam o significado dessas palavras, essa discussão foi pausada enquanto o professor explicava o que são organismos autotróficos e organismos heterotróficos. Na análise de Antonio e Cassim (2012, p. 331), a porção na qual a explicação é dada é um satélite parentético em relação ao núcleo (DIAGRAMA 14). A relação parentética não está presente no rol de relações clássicas da RST (MANN; THOMPSON, 1988), mas foi definida posteriormente. Pardo (2005) afirma que o efeito dessa relação é que o destinatário reconheça que $\mathrm{S}$ apresenta informação extra, referente a N complementando N (QUADRO 9). 


\section{Diagrama 14 - Relação parentética}

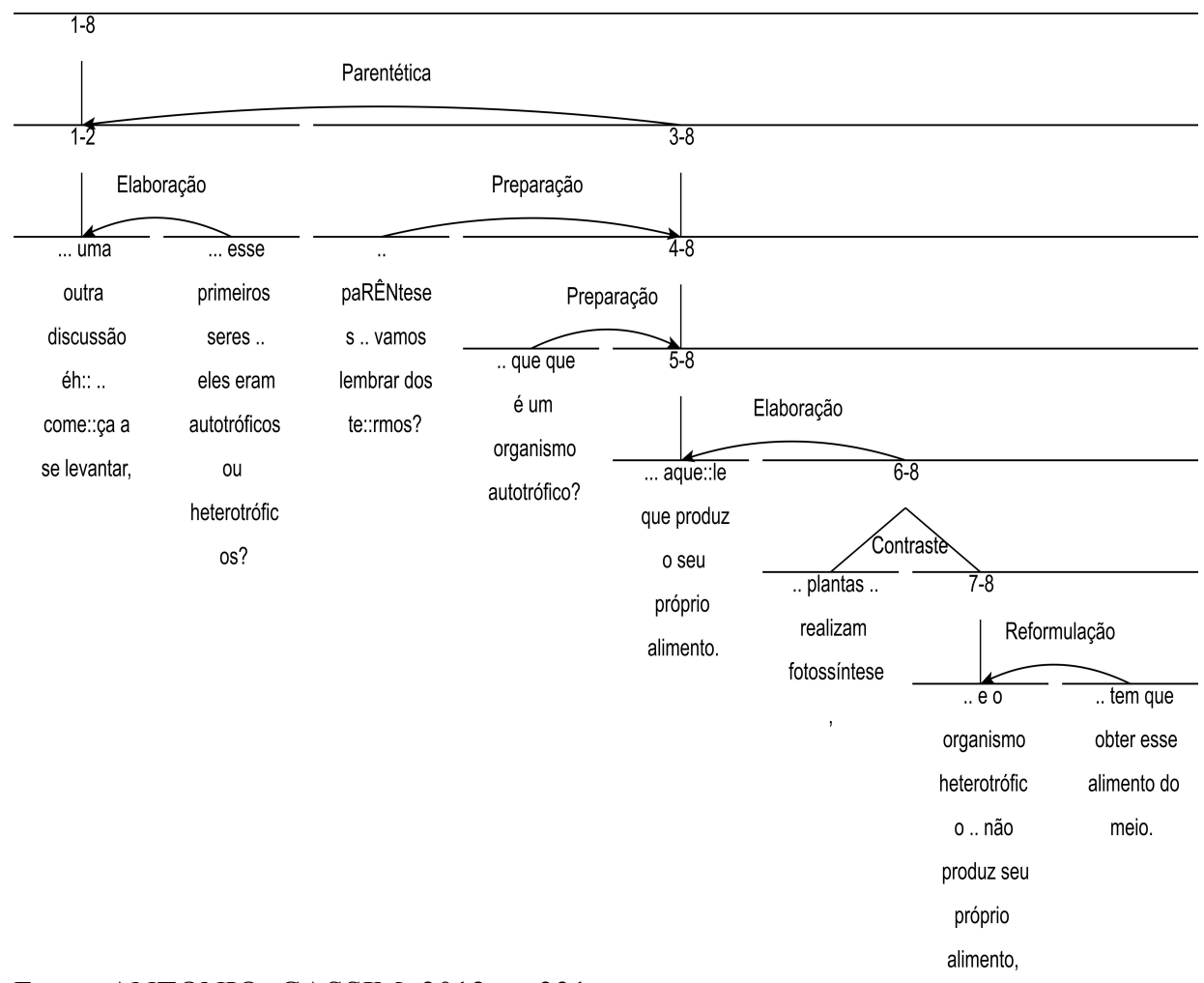

Fonte: ANTONIO; CASSIM, 2012, p. 331.

Quadro 9 - Definição da relação parentética

\begin{tabular}{|c|c|c|c|}
\hline $\begin{array}{l}\text { Nome da } \\
\text { relação }\end{array}$ & $\begin{array}{l}\text { Restrições sobre } \mathrm{N} \text { ou } \\
\text { sobre } \mathrm{S} \\
\text { individualmente }\end{array}$ & Restrições sobre $\mathbf{N}+\mathrm{S}$ & $\begin{array}{l}\text { Intenção do } \\
\text { falante/escritor }\end{array}$ \\
\hline Parentética & $\begin{array}{l}\text { Sobre N: não há. } \\
\text { Sobre S: apresenta } \\
\text { informação extra, } \\
\text { relacionada a } \mathrm{N} \text {, que } \\
\text { não está expressa no } \\
\text { fluxo principal do } \\
\text { texto. }\end{array}$ & $\begin{array}{l}\text { S apresenta informação } \\
\text { extra, relacionada a N, } \\
\text { complementado N; S } \\
\text { não pertence ao fluxo } \\
\text { principal do texto. }\end{array}$ & $\begin{array}{l}\text { O destinatário } \\
\text { reconhece que } \mathrm{S} \\
\text { apresenta } \\
\text { informação extra, } \\
\text { relacionada a } \mathrm{N}, \\
\text { complementando } \mathrm{N} \text {. }\end{array}$ \\
\hline
\end{tabular}

Fonte: PARDO, 2005, p. 140. 
Todos os informantes identificaram corretamente a função do satélite parentético em relação ao núcleo. Ao se defrontarem com o vocábulo parênteses sinalizando a relação parentética, sete informantes afirmaram não haver necessidade de sinalizar a relação, pois o conteúdo do satélite e o ato de fala seguinte do professor ("vamos lembrar dos termos?") já apontam para a natureza informacional complementar.

A análise das respostas dos informantes confirma, portanto, o pressuposto da RST de que as relações de coerência, por serem de sentido, e não de forma, podem ser estabelecidas e interpretadas independentemente de serem marcadas explicitamente por conectivos. Como explicar, entretanto, o fato de a maioria dos informantes ter considerado que a sinalização das relações por meio de conectores facilita a identificação? De acordo com Neves (1997b, p. 1), uma das mais importantes contribuições do funcionalismo para o estudo da articulação de orações é "a valorização da participação do falante na organização de seu enunciado, para expressar as relações aí envolvidas". $\mathrm{Na}$ prática, os modelos funcionalistas de gramática, sendo sistêmicos, procuram explicar, com base na pragmática, os motivos que levaram o falante a optar por uma determinada forma e não por outra diante do grande número de possibilidades disponíveis na língua. Em outras palavras, nas porções de texto utilizadas nesta pesquisa, os falantes que as produziram consideraram que o uso de um conector funcionaria como uma pista que facilitaria a identificação da relação pelos destinatários dos textos (no caso, os alunos). E os entrevistados, em sintonia com os produtores dos textos, por serem também professores, também julgaram que as pistas tornariam a identificação das relações mais clara para os alunos.

\section{Conclusões}

Este projeto teve como objetivo investigar se a falta de sinalização das relações por meio de conectivos e de MDs dificulta ou impossibilita a identificação dessas relações em aulas de curso superior.

A investigação foi realizada com a apresentação de dez excertos para professores e alunos de curso superior. Para cada excerto 
apresentado, os informantes responderam algumas perguntas para que se pudesse verificar se a relação foi reconhecida.

Inicialmente, os excertos foram apresentados aos informantes sem os conectores que ligam as porções textuais investigadas. $\mathrm{Na}$ sequência, os excertos foram apresentados com os conectores. Deve-se observar que os excertos foram produzidos originalmente com os conectores, que foram retirados para os propósitos da pesquisa quando da apresentação inicial aos informantes.

Verificou-se que, na maioria das ocorrências, a identificação das relações pelos informantes foi possível mesmo sem o conector, corroborando o pressuposto da RST de que as relações de coerência, por serem de sentido, e não de forma, podem ser estabelecidas e interpretadas independentemente de serem marcadas explicitamente por conectivos. No entanto, a maioria dos informantes considerou que a sinalização das relações por meio de conectores facilita a identificação, corroborando também o princípio funcionalista de análise, segundo o qual o falante organiza seus enunciados da forma comunicativa mais adequada para expressar as relações envolvidas na combinação dos enunciados.

\section{Referências}

ANTONIO, J. D. O texto como objeto de estudo na Linguística Funcional. In: ANTONIO, J. D.; NAVARRO, P. (Org.). O texto como objeto de ensino, de descrição linguística e de análise textual $e$ discursiva. Maringá: Eduem, 2009a. p. 61-80.

ANTONIO, J. D. Os usos do agora em elocuções formais e em entrevistas orais. Revista de Estudos da Linguagem, v. 17, p. 189-214, 2009b. <http://dx.doi.org/10.17851/2237-2083.17.2.189-214>

ANTONIO, J. D. Expressão linguística das relações retóricas de circunstância e de condição por meio de orações adverbiais temporais e por meio de orações adverbiais condicionais. Estudos Linguísticos, v. 41, n. 1, p. 128-143, 2012a. 
ANTONIO, J. D. Expression of cause, evidence, justify and motivation rhetorical relations by causal hypotactic clauses in Brazilian Portuguese. Acta Scientiarum. Language and Culture, v. 34, n. 2, p. 253-268, 2012 b.

ANTONIO, J. D.; TAKAHASHI, C. Atuação da relação retórica de elaboração na macroestrutura e na microestrutura de elocuções formais. Calidoscópio, $\mathrm{V}$. 8 , p.

174-180, 2010.<http://dx.doi.org/10.4013/cld.2010.83.02>

ANTONIO, J. D.; CASSIM, F. T. R. Coherence relations in academic spoken discourse. Linguística LII: Le Discours Parlé, p. 323-336, 2012.

BUTLER, C. S. Structure and function: a guide to three major structuralfunctional theories. Part 1: approaches to the simple clause. Amsterdam / Philadelphia: J. Benjamins, 2003.

CHAFE, W. Linguistic differences produced by differences between speaking and writing. In: OLSON, D. R. et al. (Ed). Literacy, Language and Learning: the nature and consequences of reading and writing. Cambridge: Cambridge University Press, 1985. p. 105-123.

DECAT, M. B. N. Estrutura retórica e articulação de orações em gêneros textuais diversos: uma abordagem funcionalista. In: MARINHO, J. H. C. e SARAIVA, M. E. F. (Ed.). Estudos da língua em uso: da gramática ao texto. Belo Horizonte: Editora UFMG, 2010. p.231-262.

DU BOIS, J. W. The Discourse Basis of Ergativity. Language, v. 63, p. 805-855, 1987. <http://dx.doi.org/10.2307/415719>

GIVÓN, T. Topic continuity in discourse: a quantitative cross-language study. Amsterdam: John Benjamins, 1983. <http://dx.doi.org/10.1075/tsl.3>

FORD, C. The treatment of contrasts in interaction. In: COUPERKUHLEN, E.; KORTMAN, B. (Ed). Cause, condition, concession, contrast - cognitive and discourse perspectives. Berlim: Mouton de Gruyter, 2000. p. 283-312. <http://dx.doi.org/10.1515/9783110219043.3.283>

GÓMEZ-GONZÁLEZ, M. A.; TABOADA, M. Coherence Relations in Functional Discourse Grammar. In: MACKENZIE, J. L.; GÓMEZGONZÁLEZ, M. A. (Ed.) Studies in Functional Discourse Grammar. Berne: Peter Lang, 2005. p. 227-259. 
GRIMES, J. The thread of discourse. The Hague: Mounton, 1975. $<$ http://dx.doi.org/10.1515/9783110886474>

HENGEVELD, K. Adverbial clauses in the languages of Europe. In: VAN DER AUWERA, J. (Ed.). Adverbial constructions in the languages of Europe. Berlin: Mouton de Gruyter, 1998. p. 335-419. $<$ http://dx.doi.org/10.1515/9783110802610.335>

HENGEVELD, K.; MACKENZIE, J. L. Functional Discourse Grammar. Oxford: Oxford University Press, 2008.

$<$ http://dx.doi.org/10.1093/acprof:oso/9780199278107.001.0001>

HIRATA-VALE, F. B. M. Para uma interpretação condicional de construções temporais do português: contextos de uso. Alfa, v. 52, n. 1, 167-177, 2008.

HOBBS, J. R. On the coherence and structure of discourse (Report $\mathrm{n}^{\circ}$ 35-87). Stanford: Stanford University - Center for the Study of Language and Information, 1985.

HOPPER, P.; THOMPSON, S. Transitivity in grammar and discourse. $\begin{array}{llllll}\text { Language, } & \text { v. } \quad 56, & \text { n. } & 2, & \text { p. 252-299, }\end{array}$ 1980.<http://dx.doi.org/10.1353/lan.1980.0017>

JUBRAN, C. C. A. S.; URBANO, H.; KOCH, I. G. V.; RISSO, M. S. Organização Tópica da Conversação. In: ILARI, R. (Org.). Gramática do Português Falado: níveis de análise lingüística. Campinas: Ed. da Unicamp, 1992. v. 2, p. 359-440.

MANN, W. C.; THOMPSON, S. A. Relational propositions in Discourse. Technical Report. ISI/RR-83-115. Marina Del Rey, CA: Inromation Science Institute, 1983.

. Rhetorical Structure Theory: toward a functional theory of text organization. Text, v. 8 n. 3, p. 243-281, 1988.

MANN, W. C.; MATTHIESSEN, C. M. I. M.; THOMPSON, S. A. Rhetorical Structure Theory and text analysis. In: MANN, W. C.; THOMPSON, S. A. (Ed.). Discourse description: diverse linguistic analyses of a fund-raising text. Amsterdam / Philadelphia: J. Benjamins, 1992. p. 39-77. <http://dx.doi.org/10.1075/pbns.16.04man> 
MARCUSCHI, L. A. Da fala para a escrita: atividades de retextualização. São Paulo: Cortez, 2001.

MATTHIESSEN, C.; THOMPSON, S. The structure of discourse and 'subordination'. In: HAIMAN, J.; THOMPSON, S. (Ed.) Clause Combining in Grammar and Discourse. Amsterdam / Philadelphia: J. Benjamins, 1988. p. 275-329.

NEVES, M. H. M. A Gramática Funcional. S. Paulo: Martins Fontes, 1997a.

A articulação de orações: reflexões de base funcionalista. CONGRESSO NACIONAL DA ABRALIN, 1., 1997, Maceió. Anais... Maceio, 1997b. p. 271-281.

2000.

. Gramática de usos do português. S. Paulo: Editora Unesp,

NICHOLS, J. Functional theories of grammar. Annual review of Anthropology, v. 43, p. 97-117, 1984.

$<$ http://dx.doi.org/10.1146/annurev.an.13.100184.000525>

NOVAES-MARQUES, N. B. A relação conclusiva na língua portuguesa: funções resumo, conclusão e consequência. 2014. 160p. Tese (Doutorado em Linguística e Língua Portuguesa) - Universidade Estadual Paulista Júlio de Mesquita Filho, São José do Rio Preto, SP, 2014.

PARDO, T. A. S. Métodos para Análise Discursiva Automática. 2005. 211p. Tese (Doutorado) - Instituto de Ciências Matemáticas e de Computação, Universidade de São Paulo. São Carlos-SP, 2005.

PÉREZ QUINTERO, M. J. Subordination in English: a functionalist approach. Amsterdam: Rodopi, 2002.

POLANYI, L. The linguistic discourse model: towards a formal theory of discourse structure. Cambridge, MA: BBN Laboratories, 1986.

SANDERS, T. J. M.; SPOOREN, W. P. M.; NOORDMAN, L. G. M. Toward a taxonomy of coherence relations. Discourse processes, v. 15, p. 1-35, 1992.<http://dx.doi.org/10.1080/01638539209544800>

SCHANK, R. C.; ABELSON, R. P. Scripts, plans, goals and 
understanding. Hillsdale: Erlbaum, 1977.

SCHIFFRIN, D. Discourse markers. Cambridge: Cambridge University Press, 1986.

TABOADA, M. Discourse Markers as Signals (or Not) of Rhetorical Relations. Journal of Pragmatics, v. 38, n. 4, p. 567-592, 2006.

$<$ http://dx.doi.org/10.1016/j.pragma.2005.09.010>

. Implicit and explicit coherence relations. In: RENKEMA, J. (Ed.). Discourse, of course. Amsterdam: John Benjamins, 2009. p. 127140. <http://dx.doi.org/10.1075/z.148>

VAN DIJK, T. A.; KINTSCH, W. Strategies of discourse comprehension. New York: Academic Press, 1983.

VAN DIJK, T. A. Cognição, discurso e interação. S. Paulo: Contexto, 1992.

VAN VALIN, R. D. JR. Functional linguistics. In: ARONOFF, M.; REES-MILLER, J. (Ed.). The handbook of linguistics. Malden: Blackwell Publishers, 2002. p. 250-263. 
RELIN, v. 24, n. 1, 2016. 